\title{
Factors Influencing Pediatric Dental Program Directors' Selection of Residents and Demographics of Current Directors
}

\author{
Robert F. Majewski, D.D.S., M.S.; Marcio A. da Fonseca, D.D.S., M.S.; Eric S. DeVries, \\ D.M.D., M.S.; Jan C. Hu, B.D.S., Ph.D.; Carol Anne Murdoch-Kinch, D.D.S., Ph.D.
}

Abstract: The primary goal of this study was to examine the criteria that influence rankings of candidates by advanced education program directors in pediatric dentistry. Secondary objectives were to obtain information on the resident selection process and to explore demographics of current program directors. A survey was sent in 2005 to all sixty-three program directors of pediatric dentistry residency programs accredited within the United States for the graduating class of 2007. The survey had a response rate of almost 78 percent (49/63). Respondents were requested to rank the importance of eleven factors that are typically included in the selection criteria for pediatric dentistry residents. Factors were rated on a scale of critical, very important, fairly important, somewhat important, and not important. The four highest ranked criteria by program directors were the following, in order: National Board scores, dental school clinical grades, class rank, and grade point average (GPA). Other factors ranked in descending order of perceived importance were the following: dental school basic science grades, experience in pediatric dentistry, extracurricular activities, completion of a general practice residency or advanced education in general dentistry program, the application essay, a publication or professional presentation, and private practice experience. All directors ranked personal interviews as very important to critical. Letters of recommendation from a pediatric dentistry department chairperson or faculty member were viewed more favorably than letters from dental school deans and non-pediatric dentistry faculty. Fifty-seven percent of the directors responding (28/49) were male, and 81 percent (40/49) were white, non-Hispanic. Fifty-nine percent of the directors (29/49) graduated from a residency program over twenty years ago, with 39 percent (19/49) having been a director for less than five years.

Dr. Majewski is Director, Graduate Pediatric Dentistry, Mott Children's Health Center and Hurley Medical Center, Flint, MI, and Adjunct Associate Clinical Professor, Department of Orthodontics and Pediatric Dentistry, School of Dentistry, University of Michigan; Dr. da Fonseca is Clinical Professor, Section of Pediatric Dentistry, The Ohio State University/Nation-wide Children's Hospital; Dr. DeVries is on staff in the Department of Pediatric Dentistry, Mott Children's Health Center, Flint, MI; Dr. Hu is Samuel D. Harris Collegiate Professor of Dentistry and Professor of Dentistry, Department of Orthodontics and Pediatric Dentistry, School of Dentistry, University of Michigan; and Dr. Murdoch-Kinch is Associate Professor, Department of Hospital Dentistry, School of Dentistry, University of Michigan. Direct correspondence and requests for reprints to Dr. Robert F. Majewski, Mott Children's Health Center, 806 Tuuri Place, Flint, MI 48503; 810-244-8274 phone; 810-768-7584 fax; majewski@mottchc.org.

This project was completed as part of the requirements, for Dr. DeVries, in the Graduate Program in Pediatric Dentistry at the University of Michigan in conjunction with and supported in part by Mott Children's Health Center and Hurley Medical Center, Flint, MI.

Key words: pediatric dentistry, dental education, match, demographics, trends, pediatric dental residency

Submitted for publication 10/20/08; accepted 12/18/08

$\mathrm{D}$ irectors of residency programs in medicine and dentistry have the annual task of selecting an incoming class of interns and residents. Most programs receive more applications than they have positions available. Although every program must meet accreditation standards, every program has unique characteristics. As each program is distinctive, program directors must utilize a selection program to fill residency positions with individuals who most closely meet the needs of each particular program. This selection process is critical to the success of a program. As the number of applications to programs has increased and the overall qualifications of candidates have improved, it has be- come increasingly challenging for program directors to evaluate candidates and to select residents. There has been a wide range of discussion regarding the various aspects and validity of the selection process in medicine and dentistry. ${ }^{1-20}$ However, there has not been an article reporting the evaluation process of program directors of pediatric dentistry residencies/advanced education programs. Throughout this discussion, the terms "residency" and "advanced education program" in pediatric dentistry will be used synonymously.

The National Resident Matching Program (NRMP) was developed in the early 1950 s as a way to allow both medical school graduates and hospitals 
to navigate the mutual selection process with fewer negative effects of increasing competition and forced early decisions. Following the success of the medical field in utilizing the NRMP, the Committee on Residency Education and Training of the American Association of Oral and Maxillofacial Surgeons initially established the Postdoctoral Dental Matching Program (PDMP) in 1985. The earliest participating programs were in oral and maxillofacial surgery, general practice residency (GPR), and advanced education in general dentistry (AEGD). In 1990, residencies in orthodontics, prosthodontics, and pediatric dentistry became involved. ${ }^{21}$ However, in 2008, there were only five dental specialty training or advanced training programs participating in the PDMP: oral and maxillofacial surgery, orthodontics, pediatric dentistry, GPR, and AEGD programs.

In an effort to obtain uniform, and presumably, more reliably comparable information on all applicants, in one standardized application format, many program directors utilize the Postdoctoral Application Support Service (PASS) of the American Dental Education Association. After reviewing applications and, usually, conducting selected candidate interviews, many programs utilize the PDMP to provide a uniform date for filling annual positions and to attempt to reduce the negative effects of a competitive, decentralized selection process.

Over the past few years, selection of candidates for a pediatric dental residency program has become increasingly competitive. ${ }^{22,23}$ With the number of applicants outnumbering the available positions, it would seem that the increase in applicants would make the selection process easier; however, this same increase in applications requires directors and other faculty members to devote more time and effort to the review process.

Program directors must use some criteria to sort through the applications. All pediatric dentistry residency programs are, in some ways, similar, as each must meet accreditation requirements set forth by the Commission on Dental Accreditation. However, each program has additional requirements based on individual program characteristics. Applicants also have individual professional and personal concerns, and are critically reviewing the programs to which they are applying. ${ }^{21}$ However, there have been no reports in the literature that describe the criteria that directors utilize in making selections to fill residency positions.

To address this knowledge gap, this study was conducted to evaluate the criteria that pediatric dentistry program directors use in selecting residents. General information concerning the resident selection process was also collected. Also, as part of the survey, the demographics of current pediatric dentistry program directors were collected to view trends within academia and residency administration in pediatric dentistry.

\section{Methods}

This study used a mailed survey to collect the data. A faculty member who has published guidelines for survey design ${ }^{24}$ assisted in the selection of the criteria used and the overall survey design. Faculty members pretested the survey for ease of use and time required for completion. The University of Michigan Institutional Review Board approved the survey and the study design.

In 2006, survey packages were mailed to directors of all sixty-three accredited pediatric dentistry advanced education programs in the United States. A list of directors, with address labels, was obtained from the American Academy of Pediatric Dentistry (AAPD). In addition, utilizing the AAPD website, the names and addresses of all program directors were verified and updated if necessary.

Each package included a cover letter describing the survey, its intent, and privacy issues, as well as a self-addressed, preposted return envelope. Each survey was assigned a random code number, solely to determine which programs had returned surveys. The individual tracking returns was not the same individual recording the replies. After one month, a second survey was mailed to nonrespondents. Data were collected in aggregate and entered into spreadsheets (Excel 2003, Microsoft Co., Redmond, WA). Directors' responses and trends were analyzed using simple descriptive statistics through the Statistical Package for the Social Sciences software (Version 13.0, SPSS, Chicago, IL). Statistical significance was determined at $\alpha=0.05$.

\section{Results}

Of the sixty-three surveys mailed, forty-nine were returned (first mailing response $=48$; second mailing=1) for a final combined response rate of 77.8 percent. Twenty-eight responding directors were male (57 percent). Forty respondents ( 81.6 percent) listed their ethnic origin as Caucasian, non-Hispanic; seven 
(14.4 percent) as Asian/Pacific Islander; one (2 percent) as Hispanic; and one (2 percent) listed "other." Twenty-nine (59 percent) of the directors had graduated from a pediatric dentistry residency program over twenty years ago, with a subset of sixteen ( 32 percent) having graduated over thirty years ago.

Nineteen (39 percent) respondents said they had been a director for five years or less, while thirteen ( 27 percent) had been a director between six and ten years, and the remaining seventeen ( 34 percent) had been a director for between ten and twenty years.

Forty-six (94 percent) of the reporting directors were from programs participating in the PDMP. Thirty-two programs (65 percent) did not accept residents from dental schools not accredited by the American Dental Association (ADA). Per program, the average number of applications received in 2005 was 104 , while the average number of available positions was five, resulting in an average applicant per position ratio of 20.8:1. Directors interviewed an average of twenty-five applicants. On average, combined university-hospital programs had six positions per program, university programs followed with five positions, and hospital programs averaged four positions.

Directors ranked their perceived importance of eleven factors that are typically considered in the appraisal of a candidate's application packet. Survey respondents used a five-point rating scale, ranging from not important to critical, to indicate their assessment of the importance of the listed factors. The eleven factors and the rating scale are listed in Table 1. National Board Dental Examination (NBDE) scores, clinical grades, dental school class rank, and dental school grade point average (GPA) were the four highest-rated criteria (see Table 1, Mean Score column). Although not rated significantly different from each other, these four factors were rated significantly different from all other factors ( $p$ values $<0.05$ ). Over 70 percent of directors thought these factors were either critical or very important. Following these factors in perceived importance, in descending order, were dental school basic science grades, extracurricular experience in pediatric dentistry, other extracurricular activities, completion of a GPR/AEGD or other specialty program, the application essay, and publications or professional presentations. The factor perceived as least important was private practice experience.

Seventy percent of directors reported that they did not consider an applicant from their own school higher than outside candidates. The reputation of the applicant's dental school was seen as a valuable factor, with 57.3 percent stating it to be fairly important to critical. Almost half of the respondents (46.9 percent) also considered the reputation of the pediatric dental program at the candidate's dental school as fairly important to critical (Table 2).

Letters of recommendation are also included in a candidate's application at all residency programs. Directors considered very important or critical those letters from their own peers or from a pediatric dentistry chair ( 65.3 percent) and those from a pediatric

Table 1. Perceived importance of eleven factors in a candidate's application, by percentage of total respondents and mean scores

\begin{tabular}{|c|c|c|c|c|c|c|}
\hline Factors & $\begin{array}{c}\text { Critical } \\
(5.0)\end{array}$ & $\begin{array}{l}\text { Very } \\
\text { Important } \\
(4.0)\end{array}$ & $\begin{array}{l}\text { Fairly } \\
\text { Important } \\
(3.0)\end{array}$ & $\begin{array}{l}\text { Somewhat } \\
\text { Important } \\
(2.0)\end{array}$ & $\begin{array}{l}\text { Not } \\
\text { Important } \\
(1.0)\end{array}$ & $\begin{array}{c}\text { Mean } \\
\text { Score } \\
\text { (Scale of 1-5) }\end{array}$ \\
\hline National Board scores & $26.5 \%$ & $53.1 \%$ & $20.4 \%$ & $\mathbf{0}$ & $\mathbf{0}$ & 4.06 \\
\hline Clinical grades & $14.3 \%$ & $65.3 \%$ & $18.4 \%$ & $2.0 \%$ & $\mathbf{0}$ & 3.92 \\
\hline Dental school class rank & $26.5 \%$ & $42.9 \%$ & $22.4 \%$ & $8.2 \%$ & $\mathbf{0}$ & 3.88 \\
\hline Dental school GPA & $18.4 \%$ & $53.1 \%$ & $22.4 \%$ & $6.1 \%$ & $\mathbf{0}$ & 3.84 \\
\hline Basic science grades & $2.0 \%$ & $55.1 \%$ & $34.7 \%$ & $8.2 \%$ & 0 & 3.57 \\
\hline $\begin{array}{l}\text { Externship/extracurricular experiences } \\
\text { in pediatric dentistry }\end{array}$ & $10.2 \%$ & $42.9 \%$ & $30.6 \%$ & $16.3 \%$ & 0 & 3.47 \\
\hline Extracurricular activities & $8.2 \%$ & $34.7 \%$ & $44.9 \%$ & $12.2 \%$ & 0 & 3.39 \\
\hline GPR/AEGD/other specialty completion & $10.2 \%$ & $22.4 \%$ & $32.7 \%$ & $28.6 \%$ & $6.1 \%$ & 3.02 \\
\hline Application essay & $6.1 \%$ & $24.5 \%$ & $30.6 \%$ & $36.7 \%$ & $2.0 \%$ & 2.96 \\
\hline Publication/presentations & $2.0 \%$ & $18.4 \%$ & $36.7 \%$ & $32.7 \%$ & $10.2 \%$ & 2.69 \\
\hline$>1$ year private practice experience & $2.0 \%$ & $12.2 \%$ & $22.4 \%$ & $28.6 \%$ & $34.7 \%$ & 2.18 \\
\hline
\end{tabular}

Note: The four highest ranked factors (in bold) were significantly different from all other factors $(\mathrm{p}<0.05)$. 
dental faculty member (71.4 percent). Letters from deans or associate deans were generally considered to be fairly important to not important. The letter that was considered least important was that from a general dentist in a private practice (Table 3 ).

All responding directors rated the interview as either critical (51 percent) or very important (49 percent) in the final selection process. All but one program reported having a mandatory formal interview with invited applicants. The majority ( 85 percent) of the interviews last one day, with seven programs having interviews from one and one-half to two days. Most programs ( 85 percent) do not cover any costs for the applicants' travel, with only eight programs reimbursing food costs and one program paying for lodging. Several programs mentioned that they provide food or meals on the days of the interview.

All programs had a selection committee. On average, the composition of the selection committee consisted of at least three full-time faculty members, four residents, and one or two part-time faculty members. Several directors reported that current residents participate in the interviewing of candidates, interact to some extent with the applicants during the interview day and then vote collectively, or have other opportunities to discuss their opinions with the committee prior to its making the final ranking choices. Administrative staff was also part of the committee in a few programs.

During individual interview sessions with candidates, 22.4 percent of programs have only one interviewer present per session, 38.8 percent of programs have two to three, and 38.8 percent have four or more interviewers per session. Personal interview sessions lasted less than fifteen minutes in 4.1 percent of programs, between fifteen and thirty minutes in 73.5 percent, and longer than thirty minutes in 22.4 percent.

Table 2. Importance of reputation of schools and programs in an application, by percentage of total respondents

\begin{tabular}{|c|c|c|c|c|c|}
\hline & Critical & $\begin{array}{c}\text { Very } \\
\text { Important }\end{array}$ & $\begin{array}{l}\text { Fairly } \\
\text { Important }\end{array}$ & $\begin{array}{l}\text { Somewhat } \\
\text { Important }\end{array}$ & $\begin{array}{c}\text { Not } \\
\text { Important }\end{array}$ \\
\hline $\begin{array}{l}\text { Applicant is a graduate of the dental } \\
\text { school at which the program is located. }\end{array}$ & 0 & $6.1 \%$ & $6.1 \%$ & $18.4 \%$ & $69.4 \%$ \\
\hline $\begin{array}{l}\text { Applicant's dental school has a good } \\
\text { reputation. }\end{array}$ & $8.2 \%$ & $26.5 \%$ & $22.4 \%$ & $26.5 \%$ & $16.3 \%$ \\
\hline $\begin{array}{l}\text { Applicant's dental school's pediatric dental } \\
\text { program has a good reputation. }\end{array}$ & $4.1 \%$ & $22.4 \%$ & $20.4 \%$ & $20.4 \%$ & $32.7 \%$ \\
\hline
\end{tabular}

Table 3. Importance of letters of recommendation, by percentage of total respondents

\begin{tabular}{lccccc} 
Individual Writing Letter & Critical & $\begin{array}{c}\text { Very } \\
\text { Important }\end{array}$ & $\begin{array}{c}\text { Fairly } \\
\text { Important }\end{array}$ & $\begin{array}{c}\text { Somewhat } \\
\text { Important }\end{array}$ & $\begin{array}{c}\text { Not } \\
\text { Important }\end{array}$ \\
\hline Pediatric dentistry program director & $10.2 \%$ & $55.1 \%$ & $18.4 \%$ & $16.3 \%$ & 0 \\
Pediatric dentistry faculty member & $4.1 \%$ & $67.3 \%$ & $14.3 \%$ & $14.3 \%$ & 0 \\
Non-pediatric dentistry faculty member & 0 & $12.2 \%$ & $40.8 \%$ & $38.8 \%$ & $8.2 \%$ \\
Dean & $2.0 \%$ & $8.2 \%$ & $20.4 \%$ & $42.9 \%$ & $26.5 \%$ \\
Associate dean & 0 & $6.1 \%$ & $20.4 \%$ & $44.9 \%$ & $28.6 \%$ \\
Pediatric dentist in private practice & 0 & $6.1 \%$ & $26.5 \%$ & $46.9 \%$ & $20.4 \%$ \\
General dentist in private practice & 0 & 0 & $14.3 \%$ & $51.0 \%$ & $34.7 \%$ \\
\end{tabular}

Table 4. Importance of selection committee participants in ranking candidates, by percentage of total respondents

\begin{tabular}{|c|c|c|c|c|c|c|}
\hline & Critical & $\begin{array}{c}\text { Very } \\
\text { Important }\end{array}$ & $\begin{array}{c}\text { Fairly } \\
\text { Important }\end{array}$ & $\begin{array}{l}\text { Somewhat } \\
\text { Important }\end{array}$ & $\begin{array}{c}\text { Not } \\
\text { Important }\end{array}$ & $\begin{array}{c}\text { Not } \\
\text { Reported }\end{array}$ \\
\hline Department chair/program director & $71.4 \%$ & $18.4 \%$ & $6.2 \%$ & $2.0 \%$ & 0 & $2.0 \%$ \\
\hline Full-time faculty member & $53.1 \%$ & $30.6 \%$ & $10.2 \%$ & 0 & $4.1 \%$ & $2.0 \%$ \\
\hline Part-time faculty member & $18.4 \%$ & $38.8 \%$ & $12.2 \%$ & 0 & $28.6 \%$ & $3.0 \%$ \\
\hline Residents & $20.4 \%$ & $24.5 \%$ & $24.5 \%$ & $16.3 \%$ & $12.3 \%$ & $2.0 \%$ \\
\hline Other & 0 & $8.2 \%$ & $4.1 \%$ & $2.0 \%$ & $83.7 \%$ & $2.0 \%$ \\
\hline
\end{tabular}


Table 4 shows the importance the directors said they feel that they themselves, as well as other participants, had in the ranking process. Most directors ( 89.8 percent) reported that they were at least very important in the ranking decision, followed by full-time faculty members ( 83.7 percent). Other individuals (part-time faculty members, residents, others) were given a less critical role in the final ranking of candidates. It is interesting to note that 69.4 percent of the directors stated that their residents' participation in the process was at least fairly important.

\section{Discussion}

Pediatric dentistry program directors are currently in a position to select excellent candidates for their programs. Not only has the number of applicants increased in recent years but so have average dental school GPA and National Board Part I scores, making pediatric dental residencies increasingly competitive..$^{21-23,25}$ However, while competition for residency positions has been rising considerably over the past few years, it would be logical to infer that it has become more difficult for program directors to appropriately sort through the increasing number of applications. Discovering factors that directors utilize when evaluating applications may allow directors to view how other programs rank candidates and may allow applicants for pediatric dental residencies to determine if they may be competitive for residency programs. There has been no literature evaluating all of these factors for pediatric dental programs.

The current trend, according to our study, appears to show that academic factors are the most important elements that directors look at when exploring applicant letters. These results are similar to reports on medical ${ }^{9-12,15-17}$ and oral surgery residencies. ${ }^{20}$

Pediatric dentistry is the only dental specialty that is not technique-specific, i.e., the training and practice are limited by the patient's age rather than technique. In reviewing applications, it seems possible that some candidates feel that program directors may potentially overlook academic factors and focus on personal factors during the selection process. Based on the data obtained in our study, pediatric dentistry directors valued candidates with strong academic backgrounds as much as other specialty directors do.

The applicant's score on the NBDE was the highest rated academic factor followed by clinical grades, dental school class rank, and dental school GPA (not significantly different from each other). Reports on medical residencies indicate an emphasis on National Board scores, ${ }^{12,13}$ grades, ${ }^{15,16}$ and class $\operatorname{rank}^{15,17}$ during the selection process. The NBDE is currently the only standard method of comparatively evaluating dental students across the country.

Clinical grades, GPA, and class rank indicate students' academic performance in relation to their dental school graduating class. Comparison of academic criteria has limited value when evaluating candidates from different schools. For example, a GPA of 3.5 may rank a student in the top 10 percent of students in one class or school, but may rank another student at another class or school in the middle of the class. This is likely a factor in graduate directors' utilizing National Board scores as an evaluation tool.

According to the Joint Commission on National Dental Examinations, the express purpose of the NBDE is to assist state boards in determining the qualifications of dentists who seek licensure to practice dentistry. In 2008, the Joint Commission approved a revision stating that National Board performance will be reported on a pass/fail basis starting in $2010 .{ }^{26}$ Although the intent of the examination is stated to be specifically for dentist evaluation prior to state licensure, exam scores have been used in other arenas. As indicated in this and other studies, National Board scores have been utilized to compare students from different dental schools for many purposes.

The stated revision will effectively eliminate such use of National Board scores. One major concern is likely to develop, especially among dental schools that grade courses on a pass/fail system and thus report neither GPAs nor dental class rank. For evaluation of a student from such a school for acceptance into a dental residency program, directors would have none of the four highest ranked criteria, as found in our study, to rely on.

While having experience in pediatric dentistry rated lower than basic science grades in dental school courses, it is important to note from the study that many directors considered it important for candidates to demonstrate that they have acquired experience in pediatric dentistry during dental school that extended beyond the standard predoctoral curriculum. This "additional" predoctoral experience would require students to go beyond the core dental school curriculum in the form of electives, additional clinical rotations, or other voluntary experiences. Further 
examination of the data reveals that 53.1 percent of directors rated this factor as being very important and important.

The respondents' lack of emphasis on recommendation letters from deans and associate deans is in agreement with some reports in medicine, where such letters were often described as vague, inconsistent, and unreliable predictors of resident performance. ${ }^{4,17,27,28}$

Overall, private practice experience was the least important characteristic that directors consider in the application process, a finding that is similar to studies that explored candidate selection for oral surgery residencies. ${ }^{20}$ Although it did not appear to be a negative factor, private practice experience was not rated as high as some might expect.

The interview process for advanced education programs allows individuals involved with the program to view the candidates' interpersonal skills and gather information that is not present within an application. All (100 percent) of the directors responding to our survey rated the interview as critical or very important for ranking candidates. Similar results have been found in studies on medical residencies. ${ }^{3,4,7,10,29}$

The majority of interviews cover one day, with only a few programs taking more than a full day. A one-day interview has both advantages and disadvantages for the applicants as well as the directors. Applicants may be likely to attend multiple interviews when they are shorter and the cost is lower. It may also be advantageous for the faculty to have shorter interview periods due to the increasing workload, as shown by Casamassimo et al. ${ }^{30}$ However, with shorter interview periods, selection committees may find it difficult to sufficiently evaluate every candidate.

A selection committee allows for multiple views and preselection discussion about the candidates before they are ranked. The results indicate that current residents comprise a majority of the selection committees at some programs; however, their impact on the final ranking process is likely limited. In one-third of the returned surveys, directors wrote in additional commentaries indicating that even though residents may comprise a large portion of individuals involved in the interview process, many directors allow residents to offer opinions about the candidates to the selection committee rather than participate in the actual selection of candidates.

Directors, as expected, are the most important participants in the selection committee, followed by full-time faculty members. The majority (90 percent) of directors viewed themselves as critical or very important in ranking candidates, with only two of the directors rating themselves as only somewhat important. The importance of the opinion of full-time faculty members was also expected since these are the individuals who will most likely train the residents and spend the most time with them throughout the program.

Out of the forty-nine responding program directors, 55 percent were male, and 45 percent female. This gender profile does not coincide with the current trend toward enhanced involvement of females in pediatric dentistry. For example, in 2004, dental school graduates were 58 percent male, but the majority (59 percent) of 2004 PASS applications in pediatric dentistry were female. ${ }^{25}$

However, when looking at these results in greater detail, the data show that the current trend is reflected. The average time that female directors have been in position was 5.48 years (median $=4$, mode $=1$ ), while male directors averaged 12.36 years (median=12, mode $=12$ ). Thus, while the majority of longer-standing directors are male, many more recently appointed directors are female. The number and percentage of female directors are likely to increase as more female pediatric dentists graduate and, potentially, enter academic positions.

Casamassimo et al. found that the number of faculty vacancies between 1995 and 2002 rose from 5 to 10.8 percent of pediatric dental faculty positions. Their results also showed pediatric dental faculty age twenty-nine or below represented only 2 percent of full-time faculty and 5 percent of part-time faculty, with the largest number of faculty reaching retirement age within a decade..$^{30}$

Limitations of our study include the possibility of varied interpretations of the questionnaire by the respondents, the inability to confirm the accuracy of replies, and poor recall by the respondents. Also, there is the possibility of a nonresponse bias, although with a 78 percent response rate, it is hoped that possibility was minimized. The survey findings are consistent with previous investigations of candidate selection criteria in medical and dental residencies: program directors and faculty favor candidates with the highest previous academic achievements. This information may be of value to directors as well as to potential applicants for positions in pediatric dentistry residencies. However, it is likely that factors not measured in the survey, such as personality, friendliness, and other subjective qualities, are taken into consideration during the complete selection process. 


\section{Conclusions}

The major findings of this study were the following. Among a total of eleven factors, National Board scores, clinical grades, dental school class rank, and dental school GPA were the four highest rated criteria reported by the majority of program directors in selecting pediatric dental residents. The majority of current pediatric dentistry advanced education program directors were male, Caucasian, and had graduated from a graduate program over twenty years ago.

Continued assessment of the application, interview, and ranking processes for pediatric dentistry, as well as other specialty programs, will be critical to ensure an efficient and effective selection process and to improve the potential of having a better match outcome if the number of applicants with progressively more impressive academic achievements and extracurricular credentials continues to increase.

\section{REFERENCES}

1. Marshall JR, Crowder M, Rice DG. Selection of psychiatric residents: an overview. J Nerv Ment Dis 1972;155(6):436-42.

2. Pharris JL, Van Cleve HP. The personal interview for applicant selection. J Fam Pract 1977;4(2):377-8.

3. Wagoner NE, Gray GT. Report on a survey of program directors regarding selection factors in graduate medical education. J Med Educ 1979;54:455-2.

4. Wagoner NE, Suriano JR, Stoner JA. Factors used by program directors to select residents. J Med Educ 1986;61:10-21.

5. Wagoner NE, Suriano JR. Recommendations for changing the residency selection process based on a survey of program directors. Acad Med 1992;76(7):459-64.

6. Wagoner NE, Suriano JR. Program directors' responses to a survey in variables used to select residents in a time of change. Acad Med 1999;74(1):51-8.

7. Gordon M, Lincoln JA. Selecting a few residents from many applicants: a new way to be fair and efficient. J Med Educ 1976;51:454-60.

8. Leichner P, Eusebio-Torres E, Harper D. The validity of reference letters in predicting resident performance. J Med Educ 1981;56(12):1019-21.

9. Ross CA, Leichner P. Criteria for selecting residents: a reassessment. Can J Psychiatry 1984;29(8):681-6.

10. Gong H, Parker NH, Apgar FA, Shank C. Influence of the interview on ranking in the residency selection process. Med Educ 1984;18:366-9.

11. Zagumny MJ, Rudolph J. Comparing medical students' and residency directors' ratings of criteria used to select residents. Acad Med 1992;67(9):613.

12. McCollister RJ. The use of part I National Board scores in the selection of residents in ophthalmology and otolaryngology. JAMA 1988;259(2):240-2.
13. Curtis DJ, Riordan DD, Cruess DF, Brower AC. Selecting radiology resident candidates. Invest Radiol 1989;24(4):324-30.

14. Gayed N. Residency directors' assessments of which selection criteria best predict the performances of foreignborn foreign medical graduates during internal medicine residencies. Acad Med 1991;66(11):699-701.

15. Grantham JR. Radiology resident selection: results of a survey. Invest Radiol 1993;28(1):99-101.

16. DeLisa JA, Jain SS, Campagnolo DI. Factors used by physical medicine and rehabilitation residency training directors to select their residents. Am J Phys Med Rehabil 1994;73(3):152-6.

17. Bernstein AD, Jazrawi LM, Elbeshbeshy B, Della Valle CJ, Zuckerman JD. An analysis of orthopaedic residency selection criteria. Hosp Joint Dis (Bulletin) 2002-2003;61(1\&2):49-57.

18. Poirier MP, Pruitt CW. Factors used by pediatric emergency medicine program directors to select their fellows. Pediatr Emerg Care 2003;19(3):157-61.

19. Frantsve LM, Laskin DM, Auerbach SM. Personality and gender influences on faculty ratings and rankings of oral and maxillofacial surgery residency applicants. J Dent Educ 2003;67(11):1252-9.

20. Spina A, Smith T, Marciani R, Marshall E. A survey of resident selection procedures in oral and maxillofacial surgery. J Oral Maxillofac Surg 2000;58:660-6.

21. da Fonseca MA, Pollock M, Majewski R, Tootla R, Murdoch-Kinch CA. Factors influencing candidates' choice of a pediatric dental residency program. J Dent Educ 2007;71(9):1194-202.

22. Weaver RG, Chmar JE, Haden NK, Valachovic RW. Annual ADEA survey of dental school seniors: 2004 graduating class. J Dent Educ 2005;69(5):595-619.

23. Waldman HB. Would you believe that during the 1990 s applications to pediatric dental training programs more than doubled? J Dent Child 2000;67(6):425-7.

24. Van Harrison R. Simple questionnaire studies. J Contin Educ Health Prof 1997;17:228-38.

25. Isharani SJ, Litch CS, Romberg E, Wells A, Rutkauskas JS. Demographics and quality profile of applicants to pediatric dentistry residencies. Pediatr Dent 2006;28(5):425-30.

26. Joint Commission on National Dental Examinations, American Dental Association. Update on the National Board Dental Examination. Chicago: American Dental Association, 2008.

27. Clemente M, Michener MW. The dean's letter of recommendation and internship performance. J Med Educ 1976;51(7, Pt 1):590-2.

28. Hunt DD, Maclaren CF, Carline J. Comparing assessments of medical students' potentials as residents made by the residency directors and deans at two schools. Acad Med 1991;66(6):340-4.

29. Swanson AG, Tudor CG. The experience of medical students in obtaining a residency (supplement). AAMC Graduation Questionnaire. Washington, DC: Association of American Medical Colleges, October 1986.

30. Casamassimo PS, Feigal R, Adair SM, Berg J, Stewart R. A snapshot of the U.S. postdoctoral pediatric dentistry faculty workforce, 2002. J Dent Educ 2004;68(8):823-8. 